\title{
Miniaturized Leadless Cardiac Pacemakers \\ - Can They Overcome the Problems With Transvenous Pacing Systems?
}

Yasushi Oginosawa, MD; Ritsuko Kohno, MD; Hisaharu Ohe, MD; Haruhiko Abe, MD

C ardiac pacemakers are among the most successful implantable medical devices and the only treatment for bradyarrhythmias. Despite remarkable progress achieved in the function, longevity and physical characteristics since the first implantation of a pacing system in 1958, several aspects of conventional pacing remain unresolved. The transvenous (TV) leads, in particular, remain the most

\section{Article p1589}

vulnerable component of conventional systems. In the perioperative period, the creation of a pneumothorax is a relatively common complication of the subclavian vein puncture needed to introduce the leads into the cardiac

Table. Characteristics of the Leadless Pacemaker Systems

\begin{tabular}{|c|c|c|}
\hline & $\begin{array}{l}\text { Nanostim }{ }^{\mathrm{TM}} \text { leadless } \\
\text { cardiac pacemaker }\end{array}$ & $\begin{array}{l}\text { Micra }{ }^{\mathrm{TM}} \text { transcatheter } \\
\text { pacing system }\end{array}$ \\
\hline Manufacturer & St. Jude Medical & Medtronic Inc. \\
\hline Volume, $\mathrm{cm}^{3}$ & 1.0 & 0.8 \\
\hline Weight, $g$ & 2.0 & 2.0 \\
\hline Pacing mode (sensor) & VVI/VVIR (temperature) & VVI/VVIR (accelerometer) \\
\hline Fixation mechanism & Screw-in helix & Nitinol tines \\
\hline \multicolumn{3}{|l|}{ Battery longevity, years } \\
\hline Nominal setting: $60 \mathrm{ppm}, 500 \Omega, 100 \%$ pacing & 14.7 & 9.6 \\
\hline $\begin{array}{l}\text { ISO standard: } 60 \mathrm{ppm}, 600 \Omega, 2.5 \mathrm{~V} / 0.4 \mathrm{~ms} \text {, } \\
100 \% \text { pacing }\end{array}$ & 9.8 & 4.7 \\
\hline Pivotal studies & LEADLESS $\|^{9}$ & Micra Transcatheter pacing system ${ }^{8}$ \\
\hline \multicolumn{3}{|l|}{ Study participants, n (\%) } \\
\hline All & $\begin{array}{l}526(100) \text { candidates for } \\
\text { permanent VVI pacing }\end{array}$ & $\begin{array}{l}725 \text { (100) candidates for class I or II } \\
\text { guideline-based pacing indications }\end{array}$ \\
\hline Nationality & Asians: $n=10$ (1.9) & Japanese: $n=38$ (5.2) \\
\hline \multicolumn{3}{|l|}{ Control (transvenous pacing studies) } \\
\hline Safety endpoint & Two studies of 1,660 patients & Five studies of 2,667 patients \\
\hline Efficacy endpoint & One ongoing study & - \\
\hline \multicolumn{3}{|l|}{ Outcome } \\
\hline Efficacy & $\begin{array}{l}\text { Acceptable pacing threshold and } \\
\text { sensing amplitude }\end{array}$ & $\begin{array}{l}\text { Percentage of patients with low and } \\
\text { stable pacing capture thresholds }\end{array}$ \\
\hline Safety & $\begin{array}{l}\text { Freedom from major device-related } \\
\text { adverse events }\end{array}$ & $\begin{array}{l}\text { Freedom from major system- or } \\
\text { procedure-related complications }\end{array}$ \\
\hline Follow-up duration, months & 6 & 6 \\
\hline \multicolumn{3}{|l|}{ Results } \\
\hline Implantation success rate, $\%$ & 95.8 & 99.2 \\
\hline Efficacy endpoint, \% (95\% Cl); P value & 90.0 (86.0-93.2); $P=0.007$ & $98.3 \%(96.1-99.5) ; P<0.001$ \\
\hline Safety endpoint, \% (95\% Cl); P value & 93.3 (89.9-95.9); $P<0.001$ & $96.0 \%$ (93.9-97.3); $\mathrm{P}<0.001$ \\
\hline
\end{tabular}

$\mathrm{Cl}$, confidence interval; ISO, International Organization for Standardization.

The opinions expressed in this article are not necessarily those of the editors or of the Japanese Circulation Society.

Received August 29, 2017; accepted October 3, 2017; released online October 12, 2017

Division of Cardiology (Y.O., R.K., H.O., H.A.), Department of Heart Rhythm Management (R.K., H.A.), University of Occupational and Environmental Health, Kitakyushu, Japan

Mailing address: Haruhiko Abe, MD, PhD, Department of Heart Rhythm Management, University of Occupational and Environmental Health, 1-1 Iseigaoka, Yahatanishi-ku, Kitakyushu 807-8555, Japan. E-mail: haru-abe@med.uoeh-u.ac.jp

ISSN-1346-9843 All rights are reserved to the Japanese Circulation Society. For permissions, please e-mail: cj@j-circ.or.jp 
chambers. ${ }^{1}$ Shortly after their implantation, leads may dislodge, despite the presence of fixation devices, or perforate the myocardial wall. ${ }^{2}$ Adverse events that may occur in the longer term include lead fractures or infections, insulation breakdown, venous obstructions and tricuspid regurgitation. ${ }^{3,4}$

The implantation of the pulse generator in a subcutaneous pectoral pocket is another weakness of conventional TV systems, because of complications with pain, limitation of shoulder motion, hematoma, erosion, infection and cosmetic dissatisfaction..$^{\mathbf{5} 6}$ It is particularly noteworthy that an infection of the pacing system often requires its total extraction. ${ }^{7}$

Leadless transcatheter pacing (TCP) was conceived over 40 years ago, in the hope of eliminating the complications associated with TV leads, but was initially impractical. Progress in battery technology and innovations in electrical integrated circuits have increased the longevity of the devices, and enabled the introduction of two bipolar, singlechamber, ventricular, rate-responsive, leadless pacing systems into clinical practice. Their efficacy and safety, including success and complication rates of the implant procedures and electrical stability of the systems, have been studied worldwide (Table). ${ }^{89}$ In this issue of the Journal, Soejima et $\mathrm{al}^{10}$ report the results of their study of differences between Japanese patients and patients from other regions of the world for use of cardiac pacemakers. Despite the smaller body dimensions of Asian patients, they found no differences in the rates of major complications or in the electrical pacing characteristics of the 2 study groups. Body size is one determinant of the strategic choice of pacemaker, because a low body mass index increases the risk of postprocedural complications associated with TV lead systems. ${ }^{11}$ Despite the absence of significant differences in the rates of major complications between Japanese patients and those from other countries, the benefit conferred by TCP compared with conventional TV pacing systems might be greater for Japanese. ${ }^{1}$

It is, however, uncertain, whether TCP will be equally accepted by Japanese and non-Japanese patients. International differences have been observed in the implantation rates of new pacing systems. In a worldwide survey, the implantation rate of new pacemakers was 927 per million populations in Germany, 767 per million in the United States, and a much lower 277 per million in Japan. ${ }^{\mathbf{1 2}}$ These regional differences in pacemaker implantation rates have been attributed to differences in (a) reimbursement schedules, (b) indications for pacemaker implantation for bradyarrhythmias, and (c) cultural acceptance of device implantations. ${ }^{13}$ One of the most noteworthy observations made by Soejima et al is a significantly lower satisfaction expressed in the recovery phase by Japanese patients, in contrast to the Japanese physicians who were similarly satisfied with the TCP implantation as physicians from other countries. ${ }^{10}$ The authors hypothesize that the Japanese patients' dissatisfaction was related to minor complications, such as congestive heart failure or worsening of atrial fibrillation. The prevalence of congestive heart failure was higher and the pacing indications associated with atrial fibrillation were fewer among the Japanese than among the patients from other countries. The reasons for the negative response expressed by the Japanese patients remain, nevertheless, unclear because detailed information regarding these minor complications of TCP are lacking for non-Japanese patients, and because of a relatively shorter follow-up. The incidence of minor complications and a longer follow-up are needed to clarify the cause of dissatisfaction in Japanese patients.

TVP has several advantages compared with first-generation of TCP systems, namely, capability of physiological atrioventricular and biventricular pacing, reliable long-term function, including battery longevity, advanced operations such as measurements of thoracic impedance to monitor heart failure and respiratory disorders, and a higher rateadaptive sensor technology. ${ }^{\mathbf{1 4}, 15}$ Leadless pacing is, nevertheless, promising, on a road oriented in the direction of multisite stimulation combined with defibrillation. However, its clinical applications should be cautiously selected on a case-by-case basis, especially in patients presenting with congestive heart failure or pacing indications unrelated to atrial fibrillation, such as sinus node disease or atrioventricular block because, for the time being, it remains a single-chamber, non-physiological device.

\section{References}

1. Kotter J, Lolay G, Charnigo R, Leung S, McKibbin C, Sousa M, et al. Predictors, morbidity, and costs associated with pneumothorax during electronic cardiac device implantation. Pacing Clin Electrophysiol 2016; 39: 985-991.

2. Akbarzadeh MA, Mollazadeh R, Sefidbakht S, Shahrzad S, Bahrololoumi Bafruee N. Identification and management of right ventricular perforation using pacemaker and cardioverterdefibrillator leads: A case series and mini review. J Arrhythm 2017; 33: $1-5$.

3. Olgun H, Karagoz T, Celiker A, Ceviz N. Patient- and leadrelated factors affecting lead fracture in children with transvenous permanent pacemaker. Europace 2008; 10: 844-847.

4. Sridhar AR, Lavu M, Yarlagadda V, Reddy M, Gunda S, Afzal $\mathrm{R}$, et al. Cardiac implantable electronic device-related infection and extraction trends in the U.S. Pacing Clin Electrophysiol 2017; 40: $286-293$.

5. Kiuchi K, Okajima K, Tanaka N, Yamamoto Y, Sakai N, Kanda G, et al. Novel compression tool to prevent hematomas and skin erosions after device implantation. Circ J 2015; 79: $1727-1732$.

6. Polyzos KA, Konstantelias AA, Falagas ME. Risk factors for cardiac implantable electronic device infection: A systematic review and meta-analysis. Europace 2015; 17: 767-777.

7. Okamura $\mathrm{H}$. Lead extraction using a laser system: Techniques, efficacy, and limitations. J Arrhythm 2016; 32: 279-282.

8. Reynolds D, Duray GZ, Omar R, Soejima K, Neuzil P, Zhang $\mathrm{S}$, et al. A leadless intracardiac transcatheter pacing system. $N$ Engl J Med 2016; 374: 533-541.

9. Reddy VY, Exner DV, Cantillon DJ, Doshi R, Bunch TJ, Tomassoni GF, et al. Percutaneous implantation of an entirely intracardiac leadless pacemaker. N Engl J Med 2015; 373: $1125-$ 1135

10. Soejima K, Asano T, Ishikawa T, Kusano K, Sato T, Okamura $\mathrm{H}$, et al. Performance of leadless pacemaker in Japanese patients vs. rest of the world: Results from a global clinical trial. Circ $J$ 2017; 81: 1589-1595.

11. Guo JP, Shan ZL, Guo HY, Yuan HT, Lin K, Zhao YX, et al. Impact of body mass index on the development of pocket hematoma: A retrospective study in Chinese people. $J$ Geriatr Cardiol 2014; 11: 212-217.

12. Mond HG, Proclemer A. The 11th World Survey of Cardiac Pacing and Implantable Cardioverter-defibrillators: Calendar year 2009. A World Society of Arrhythmia's project. Pacing Clin Electrophysiol 2011; 34: 1013-1027.

13. Jang SW, Rho RW, Kim TS, Kim SH, Shin WS, Kim JH, et al. Differences between Korea and Japan in physician decision making regarding permanent pacemaker implantation. Korean Circ J 2016; 46: 654-657.

14. Mulpuru SK, Madhavan M, McLeod CJ, Cha YM, Friedman PA. Cardiac pacemakers: Function, troubleshooting, and management: Part 1. J Am Coll Cardiol 2017; 69: 189-210.

15. Madhavan M, Mulpuru SK, McLeod CJ, Cha YM, Friedman PA. Advances and future directions in cardiac pacemakers: Part 2. J Am Coll Cardiol 2017; 69: 211-235. 